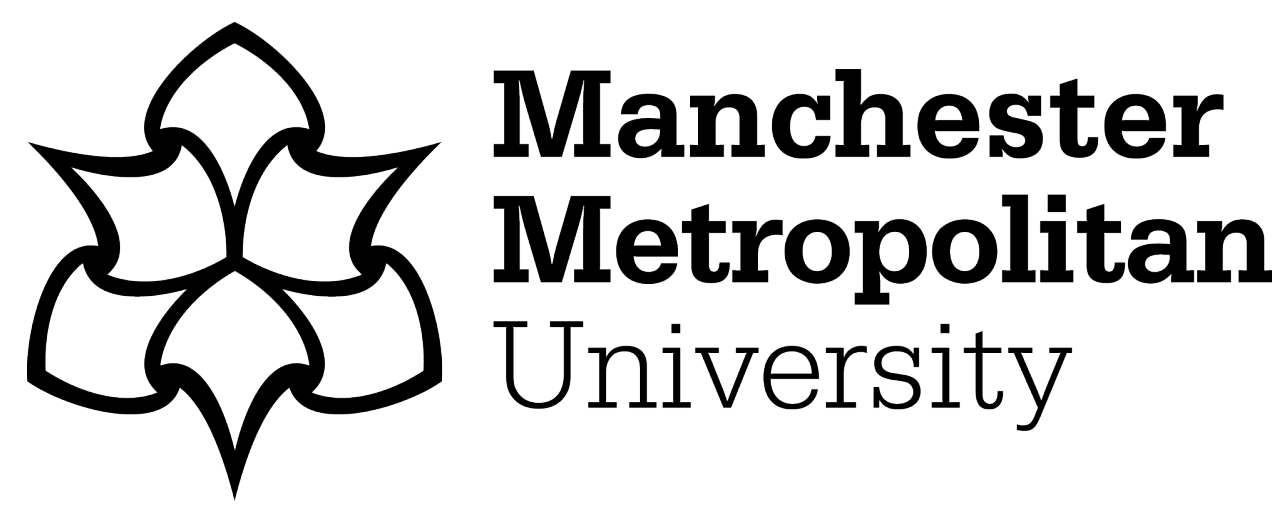

Yusof, Nor'Aini, Tabassi, Amin Akhavan and Esa, Muneera (2019) Going beyond environmental regulations-The influence of firm size on the effect of green practices on corporate financial performance. Corporate Social Responsibility and Environmental Management, 27 (1). pp. 32-42. ISSN 15353958

Downloaded from: https://e-space.mmu.ac.uk/627685/

Version: Accepted Version

Publisher: Wiley

DOI: https://doi.org/10.1002/csr.1771

Please cite the published version 


\section{Going Beyond Environmental Regulations - the influence of Firm Size on the effect of Green Practices on Corporate Financial Performance?}

\section{ABSTRACT}

Despite the various environmental regulations to address the negative effect of construction activities on the environment, compared to other industries, the construction sector is still slow in implementing green practices (GPs). To encourage construction firms to implement GPs, these firms should be convinced that GP is a financially viable endeavour. Additionally, it was argued that the effect of GPs on corporate financial performance (CFP) differs according to the size of construction firms. This paper aimed to test the arguments by analysing the influence of GPs on CFP and investigating whether firm size influences or moderates the effect. A survey was employed to gather information from Malaysian construction firms and the data were analysed using the partial least squares structural equation modelling (PLS-SEM). The findings indicate that green supplier management, green subcontractor management and green project management have significant and positive effects on CFP and large firms with high level of green business practice and green project management gained higher CFP than small and medium enterprises. The findings provide empirical evidence on the variance of the effects of GPs and firm size on CFP. The findings imply that there should a flexible approach to encourage GPs in construction industry. Policy makers, regulators and managers should consider firm size and focus on high level of green business practice and green project management to improve firms CFP. 
Keywords: Green practice; environmental regulation; corporate financial performance; firm size; construction firm

\section{Introduction}

Environmental degradation has been recognised as a global issue and governments have been asked to take immediate actions to address the problems. While global policies and programmes signify the construction sector among the most promising for sustainable development (Tabassi et al., 2016) compared with other industries, the construction industry has been slow in the implementation of green practices (GPs) (Oshodi \& Aigbavboa, 2017). Several legislative and policy measures have been employed by developing countries to support GPs (Lai et al., 2017; Yu et al., 2018) and construction firms have been encouraged to go beyond complying with regulations; such as greater corporate commitment towards environmental agenda by embracing into ISO 140001 (Zhao et al., 2012).

Malaysia envisaged to become a high-income country by 2020, faces many environmental challenges in terms of high carbon emission, energy usage and construction waste due to rapid infrastructures development and higher demand for real estate in its major cities (CIDB, 2015). These challenges have prompted the government to launch the Construction Industry Transformation Programme (CITP) 2016-2020 where environmental sustainability is included as its Strategic Trust 2 with one of environmental targets is to achieve a 40 per cent reduction in greenhouse gas emissions by the year 2020 (CIDB, 2015). To support the achievement of this target, a robust rating tool for 
environmental sustainability called MyCREST (Malaysian Carbon Reduction and Environmental Sustainability Tool) that evaluates carbon emission throughout a facility's life cycle together with green incentives - Green Investment Tax Allowance and Green Income Tax Exemption were introduced in 2017 (CIDB, 2018). Subsequently, MyCREST was adopted in all large public infrastructure projects and 20 large private projects as pilot programmes (CIDB, 2015); creating a new demand within the industry for green consultants, contractors, subcontractors and suppliers. Like most developing countries, the effort towards GPs is often reactive (Amran et al., 2016). It is not surprising, despite the above-mentioned efforts, only $13.7 \%$ of construction and demolition waste was recycled and a limited number of firms have adopted GPs at the appropriate level (CIDB, 2018). There is an urgent need to identify effective strategies to boost GPs among construction players and is the aim of the present study.

Generally, green practice (GP) refers to practices that cause less harm to the environment (Liu \& Lin, 2016). Large firms usually face intense public scrutiny to be environmental responsible, due to their visibility and the huge scale of their construction activities that may deteriorate the environment (Darnall et al., 2010; Song et al., 2017), are expected to spearhead GP initiatives beyond environmental regulations fulfilment, as part of their corporate social responsibility (Damert \& Baumgartner, 2017). In certain developing countries like Malaysia and China where GP is not prevalent, GPs are imposed on all large public infrastructure projects, and large private firms and public listed companies are expected to be environmental management certified (CIDB, 2015; Jiang \& Wong, 2016). An increase in corporate financial performance (CFP), such as profitability and cost reduction, is argued to be vital to encourage GP adoption (Ahmed et 
al., 2018). Therefore, we argued that to encourage construction firms to implement GPs, these firms should be convinced that GP is a financially viable endeavour. Research on GP is substantial but until now there are no conclusive results about the relationship between GP and CFP and how large and smaller firms influence the relationship. Segarra Oña (2013) revealed that there was no evidence that firms with a high level of GP have a higher CFP than firms with a low level of GP. Li et al. (2017) found only a weak relationship between the GPs and CFP of the 500 top companies in the US. In the construction sector, Siew et al. (2013) found either no significant or only a weak relationship between GPs and CFP. In contrast, there are studies that reveal the financial benefits of GPs in industries other than construction (Porter \& Van der Linde, 1995; Gotschol et al., 2014; Miroshnychenko et al., 2017). Firms that are forerunners of GPs have the privilege of imposing relatively higher prices for their products or services and gaining higher CFP (Porter \& Van der Linde, 1995). However, the positive relationship is not the same across all areas of GPs and firm size. Gotschol et al. (2014) found that environmental management helps firms to sustain CFP, but the green supply chain has a greater effect and provides a higher CFP than the former. Miroshnychenko et al. (2017) showed that pollution control and green supply chain increase CFP, but ISO 14001 reduces CFP. Also, scholars found that the moderating effect of firm size on GPs-CFP link is different for large and small and medium-sized enterprises (SMEs) (Hou et al., 2016; Nguyen et al., 2018; Simpson, 2012). A study in the medical, food, and manufacturing sectors ascertained that the moderating role of firm size with large firms has a greater effect of green supply chain on CFP than the SMEs (Wang et al., 2018). SMEs can be encouraged to be more environmental, customer and community focus if 
they can improve their knowledge, collaboration and flexibility capabilities (Choi et al., 2019). These studies highlight a variance of the effects in different areas of GP (such as green supply chain, pollution control and green business practice) and firm size (between large and SMEs) on CFP.

To clear up the confusion, it is important to consider the effects of different areas of GP on CFP and to investigate whether firm size moderates such effects. Specifically, the objectives of the study are two-folds; i. to identify the influence of GPs on CFP and ii. To determine whether firm size influences or moderates this effect. This study makes both theoretical and practical contributions. Theoretically, we intend to provide empirical support for an on-going debate on the fact that the influence of GPs on CFP will depend on the areas of GP and firm size, which prior studies ignored. Additionally, by studying firms in the construction industry that faced serious environmental problems, the present study provides a greater understanding of the prerequisite of GP adoption in the unique construction industry characteristics. Practically, with the many financial challenges facing construction firms, stricter environmental regulations, and intense expectation from the public for firms to be environmentally responsible, the present study guides policy makers on how to encourage GP among the industry players and helps managers to strategies on GPs that can effectively boost their CFP in relation to its firm size.

\section{Literature Review and Hypotheses}

CFP relates to financial implication or economic effects of GPs on a business or firm

(Trumpp \& Guenther, 2017). Studies have used multidimensional construct using objective and subjective indicators to conceptualised CFP (Trumpp \& Guenther, 2017; 
Sáez-Martínez et al., 2016). In the present study CFP is measured using subjective perception (Aragón-Correa et al., 2008) on improvement of profit (Ahmed et al., 2018) and average return on investment (Aragón-Correa et al., 2008; Leonidou et al., 2016), reduction in project costs and in operational costs (Torugsa et al., 2012), and enhance in economic growth (Leonidou et al., 2016). Previous studies showed that construction firms are engaged in four major areas of GP - green business practice, green supplier management, green subcontractor management and green project management (Martens \& Carvalho, 2017; O'Connor et al., 2016). High level of GPs refers to practices that go beyond complying environmental regulations; aimed at reducing or eliminating the negative environmental impacts by integrating environmental considerations in their operations (Delmas \& Toffel, 2004; Segarra-Oña et al., 2013). Examples of such practices are implementation of environmental management system (such as ISO14000 certification) or requesting subcontractor and supplier to implement environmental management system (Mondéjar-Jiménez et al., 2013). On the other hand, low level of GPs denotes to practices that are restricted to complying with environmental regulations (Segarra-Oña et al., 2013).

Green business practice refers to a firm's capacity to accomplish its business objectives and stakeholder needs by assimilating environmental mission into its business strategies (Harmon et al., 2009). Green business practice covers business activities that include the firm's processes and actions that are pro-environmental (Liang \& Liu, 2017). It also refers to the firm's strategy that is focussed on being responsible with the environment (Chang, 2017). Firms are being asked to exercise CSR; shape their corporate systems to accomplish a higher level of responsibility by balancing between business necessities, 
needs of shareholders, and those of society (Ayuso \& Navarrete-Báez, 2018). Firms are under pressure to continually improve their products and processes to be environmentally friendly so as to attain competitive advantage (Albort-Morant et al., 2018). Firms that are pioneers in engaging in CSR activities in the environment received a higher monetary gain (McPeak \& Tooley, 2008). Firms with greater green investment are found to gain more financially in terms of higher net profit rate (Liang \& Liu, 2017; Song et al., 2017). Similarly, firms with a high degree of GP enjoyed a better CFP as compared to firms with low GP (Lewandowski, 2017). The first hypothesis is:

$H_{1}$ : Green business practice has a positive effect on the CFP of construction firms.

Supplier management refers to the management of the flow of construction materials from the extraction phase to the consumption of products and services (Rao \& Holt, 2005). Green supplier management refers to considering the environment in procurement, transportation, design, production, consumption, preservation and destruction activities (Zhu et al., 2008; Balasubramanian \& Shukla, 2017). Examples of green supplier management are the environmental consideration in selecting suppliers such as opting for suppliers that do not use harmful materials, requiring suppliers to adopt ISO 14000 and an environmental audit for the suppliers' internal management (Zhu et al., 2008; Lintukangas et al., 2015). Although engaging in green supplier management may require greater coordination and thus, increase in complexity and cost; effective collaboration among all players can limit the cost and improve CFP (Ahmed et al., 2018). In industries other than construction, green supplier management has led to higher CFP (Gotschol et al., 2014; Miroshnychenko et al., 2017). Thus, the second hypothesis is: 
$\mathrm{H}_{2}$ : Green supplier management has a positive effect on the CFP of construction firms.

The multi-specialisation and various construction project sites require construction firms to contract out specific work to subcontractors (Yin et al., 2014). These subcontractors have their own objectives, focus only on their scope of work, and use their own tools, procedures, and industry specifications (Shi et al., 2016). Green subcontractor management refers to selecting green certified or ISO14000 subcontractors (Rao \& Holt, 2005). The application of 'lean' procurement in the subcontracting process leads to the improvement of the communication and collaboration between the contractors and subcontractors and, thus, achieves a greater financial benefit (Yin et al., 2014). The third hypothesis of the study is:

$H_{3}$ : Green subcontractor management has a positive effect on the CFP of construction firms.

Green project management refers to the integration of the construction project phases with the environmental agenda (Yusof et al., 2017; Lam et al., 2011). Apart from the time, cost and quality yardsticks that dominate the decision-making in project implementation, project management practice encourages environmental goals to be valued among project members (Silvius et al., 2017) and this can be effectively done through collaborative decision making and mutual agreement (Yusof et al., 2016). Green project management also involves incorporating environmental objectives and the local ecosystem as key considerations in project implementation (Carvalho \& Rabechini, 
2017). The role of project managers is crucial in ensuring that the environmental agenda is pursued throughout the project phases (Banihashemi et al., 2017). When green project management is implemented, it encourages environmental principles to be integrated in the fragmented project phases, reduces wastage, efficient use of resources and, subsequently, improves CFP (Banihashemi et al., 2017; Rao \& Holt, 2005). Therefore, the fourth hypothesis is:

$\mathrm{H}_{4}$ : Green project management has a positive effect on the CFP of construction firms.

A variable is considered to have a moderating effect if it strengthens or changes the nature of the correlation between the exogenous and endogenous variables (Georg et al., 2016). Firm size measured either by the number of full-time staff or the amount of capital, with large firms are more likely to engage in many economic and non-economic business activities (Liang \& Liu, 2017). In this sense, firm size is especially valuable for projecting the impact of firm activities and the environmental issues that need to be handled (Darnall et al., 2010). Firm size has been frequently acknowledged to have a moderating effect, but there are conflicting results on the moderating role of large and smaller size firms (Hou et al., 2016; Simpson, 2012). SMEs are found to increase the relationship between marketing competence (i.e developing marketing strategies faster and cheaper) and CFP, than large firms (Ko \& Liu, 2017). Small firms with a low pollution level because of its limited extent of activities, were found to have higher net profit rate than large firms (Liang \& Liu, 2017). Similarly, SMEs have the flexibility to be more environmental responsible because of its simpler organisational structure and thus, faster decision-making, have stronger effect on CFP compared to the large firms (Hou et al., 
2016). In contrast, SMEs constrained by resources, knowledge and skills face huge challenge to adopt GPs (Wu, 2017). Large firms armed with additional resources, skills and technology can minimize waste and enhance CFP without difficulty than smaller firms (Simpson, 2012). In addition, large firms braced with information sharing, collaboration, compliance with regulations, are found to have greater influence of green supplier management and green subcontractor management on CFP (Wang et al., 2018). These studies demonstrate the variance of moderating effects of firm size on the relationship between GPs and CFP. Therefore, the fifth hypotheses are:

$H_{5 a}:$ Firm size moderates the relationship between green business practice and CFP of construction firms.

$H_{5 b}$ : Firm size moderates the relationship between green supplier management and CFP of construction firms.

$H_{5 c}$ : Firm size moderates the relationship between green subcontractor management and CFP of construction firms.

$H_{5 d:}$ Firm size moderates the relationship between green project management and CFP of construction firms.

\section{Research Methods}

Research Instrument

A quantitative survey was used to collect the data. The reason to employ a quantitative study is because of the predictive nature of the study; to determine relationship between GPs and CFP and to identify how firm size influences the relationship. Therefore, data need to be gathered using a structured research instrument (a quantitative survey) based 
on well define hypotheses where quantifiable results were sought. The survey with 23 items consists of three parts; background information of the firm (4 items), the aspects of green practices (14 items) - green business practice, green supplier management, green subcontractor management and green project management and CFP (5 items). Green business practice was measured using five items suggested by Chang et al. (2017) and Liang and Liu (2017). Green supplier management ( 3 items) adapted from Rao and Holt (2005) and Balasubramanian and Shukla (2017), green subcontractor management (3 items) was derived from Yin et al. (2014) and Shi et al. (2016) and green project management (3 items) was sourced from Banihashemi et al. (2017) and Carvalho and Rabechini (2017). CFP was measured using 5 items adapted from Aragón-Correa et al., (2008), Leonidou et al. (2016) and Torugsa et al. (2012). A five-point Likert scale, from strongly disagree -1 to strongly agree -5 , was used to measure each item. Three experts were consulted for pre-testing to ensure that the survey questions were clear, succinct, not vague, without dubious meaning, and that the terminologies were familiar to the respondents.

\section{Sample and Data}

The lists of the construction firms were obtained from the Malaysian Construction Industry Development Board (CIDB), the Real Estate and Housing Developers' Association Malaysia (REHDA), the Association of Consulting Engineers Malaysia and Malaysian Institute of Architects. Since the lists contained no other information apart from the names and addresses of the firms, representative sampling could not be employed. Therefore, a census sampling technique was employed. Contact was made to the firms through 
emails or telephones to verify their locations and to solicit their commitment to participate in the study. Subsequently, the survey forms were mailed to 600 construction firms that agreed to participate, followed by telephone calls to the targeted respondents notifying them about the survey forms. The targeted respondents were those who had knowledge about the firm's GPs and financial performance and involved in the decision making. Two rounds of reminders were sent to the respondents and the data collection end after three months. A total of 210 usable responses were returned (with a response rate of $35 \%$ ) and analysed. The minimum required sample size calculated using the gamma-exponential method was 146 (at the power of 0.8 , significant at 0.05 and absolute significant path coefficient $=0.197)$. By consideration, the usable response was 210 , which surpassed the minimum required sample size and, likewise, showed a power above 0.90 , meaning that it would have led to more precise and replicable measures (Kock \& Hadaya, 2016). The profile of respondents revealed that $26 \%$ were from consulting firms, contractors (44\%) and real estate development firms (30\%). Majority of the firms (38\%) were established for more than 20 years, $36 \%$ were established between 11 to 20 years and $26 \%$ were established between 6 to 10 years. The size of the firms was classified according to the National SME Development Council of Malaysia for firms established before 2013 . There were $44 \%$ of small firms (less than 20 employees), $28 \%$ were medium sized (between 20 and 50 employees) and large firms (more than 50 employees), respectively. The one-way analysis of variance or ANOVA was used to substantiate that the respondents had similar knowledge and understanding of the firm goals, activities and performance. The result shows that $p$ value $=0.458$, indicating that there is no significant difference between the respondent's knowledge capability. 
Since the data of all constructs were collected using the same method (quantitative survey) from the same respondents at one point in time, there is a possibility of a presence of a common method bias, which may exaggerate or understate the results and thus lead to wrong conclusions (Christopher et al., 2011). To ensure the problem does not arise in the study, a common method bias was checked using the full collinearity VIF test (Kock, 2015). The result shows the average full collinearity of the variance inflation factor (AFVIF) of 2.178, which satisfies Kock (2017)'s 3.3 limit, indicating the absence of common method bias in the study.

\section{Data Analysis technique}

To test the hypothesis and achieve the objectives, the partial least squares structural equation modelling (PLS-SEM) of WarpPLS Version 6.0 was applied, involving two steps of evaluation: step 1 - evaluation of the measurement model; step 2 - evaluation of the structural model. Several criteria were considered for choosing PLS-SEM; i) if the study is prediction oriented (Ramayah et al., 2017; Rigdon et al., 2016), ii) if the data characteristics is not normally distributed (Hair et al., 2017), and iii) if the study model involves formative and reflective constructs (Memon et al., 2017; Hair et al., 2017). In the present study, the objectives are prediction in nature - to identify the key green practices that significantly affect corporate financial performance and the influence of firm size on the relationship between green practices and corporate financial performance. Second, two normality tests were conducted; a normality test using Jarque-Bera was provided following Kock (2016) suggestion - showing that more than one variable is not normal, and a Shapiro-Wilk test $(p>0.05)$ (Razali \& Wah, 2011) showed that the data were significant at 0.000 ; indicating that the data was not normal. Third, the structural 
model of the present study consists of both the reflective and formative constructs. These criteria justify the appropriate use of PLS-SEM. The following sections specify the process of analysis and results.

\section{Results}

\section{Step 1 - Measurement Model Evaluation}

In the measurement model evaluation, the reliability and validity of all of the constructs were examined. Our model had both reflective and formative items. For the reflective items, the internal consistency, the indicator reliability, the convergent validity, and the discriminant validity were used for the evaluation of the measurement model (Hair et al., 2017). The composite reliability (CR) was used to check the internal reliability (Robinson, 2018). The $C R$ of all the reflective constructs was above 0.7 , complying with the minimum threshold of Hair et al. (2017). The convergent validity tested using the average variance extracted (AVE) should be that this value surpasses 0.5 in all of the constructs, complying with the threshold of Fornell and Larcker (1981). Also, the measurement model had satisfactory convergent validity with $P$ values for all items that were $<0.001$, and the loadings were greater than 0.5, which was in accordance with Kock's (2014) rules for reflective items. Thus, the reflective constructs satisfy reliability and convergent validity requirements. Table 1 presents the measurement model evaluation for the reflective constructs.

Table 1. Measurement model evaluation for the reflective constructs.

\begin{tabular}{lccc}
\hline Construct/Item & Factor Loadings & CR & AVE \\
\hline Green Business Practice (GBP) & & 0.904 & 0.653 \\
GBP1 & 0.829 & & \\
GBP2 & 0.811 & & \\
GBP3 & 0.786 & & \\
\hline
\end{tabular}




\begin{tabular}{lccc}
\hline GBP4 & 0.815 & & \\
GBP5 & 0.798 & 0.902 & 0.754 \\
Green Supplier Management (GSM) & 0.853 & & \\
GSM1 & 0.896 & & \\
GSM2 & 0.855 & 0.905 & 0.760 \\
GSM3 & & & \\
Green Subcontractor Management (GSCM) & 0.844 & & \\
GSCM1 & 0.9 & 0.877 & 0.705 \\
GSCM2 & 0.87 & & \\
GSCM3 & & & \\
Green Project Management (GPM) & 0.878 & \\
GPM1 & 0.874 & & \\
GPM2 & 0.761 & & \\
GPM3 &
\end{tabular}

$\mathrm{CR}=$ Composite Reliability; $\mathrm{AVE}=$ Average Variance Extracted

Subsequently, the discriminant validity of all constructs was checked using cross-loadings and inter-correlation indicators. The test showed that each indicator load was greater than any opposing construct, fulfilling the criteria of Hair et al. (2012). In addition, the square root of the AVE of a single construct was less than the value of the inter-correlations between the construct and other model constructs. The two tests ratified the discriminant validity of all the constructs. Table 2 shows the results of the discriminant validity of the constructs.

Table 2. Discriminant validity.

\begin{tabular}{lcccc}
\hline Variables & GBF & GSM & GSCM & GPM \\
\hline GBP & $0.808^{*}$ & & & \\
GSM & 0.598 & $0.868^{*}$ & & \\
GSCM & 0.619 & 0.623 & $0.872^{*}$ & \\
GPM & 0.664 & 0.537 & 0.504 & $0.839^{*}$ \\
\hline
\end{tabular}

*Square root of the AVEs on the diagonal GBP=green business practice, GSM= green supplier management, GSCM= green subcontractor management, GPM= green project management

The measurement model for the formative items was evaluated using the convergent validity, the collinearity amongst the indicators, and the significance and relevance of the outer weights (Hair et al., 2017). The $P$ values for all the formative items were significant 
at $<0.001$ and the variance inflation factors (VIFs) among the associated formative construct indicators were less than 3.3, fulfilling Kock's (2014) cut-off point for formative items. The full collinearity VIFs of the formative construct was 1.604, fulfilling Kock's 3.3 threshold. Hence, the results demonstrate that the study satisfies the requirement for the formative construct. Table 3 presents the evaluation of the measurement model for the formative construct.

Table 3. Measurement model evaluation for the formative construct.

\begin{tabular}{ccccc}
\hline Variable & Weights & P-Value & VIF & Full collinearity VIFs \\
\hline Corporate Financial Performance - CFP & & & & 1.604 \\
CFP1 & 0.243 & $<0.001$ & 2.423 & \\
CFP2 & 0.264 & $<0.001$ & 3.203 & \\
CFP3 & 0.24 & $<0.001$ & 2.269 & \\
CFP4 & 0.25 & $<0.001$ & 2.498 & \\
CFP5 & 0.232 & $<0.001$ & 1.899 & \\
\hline
\end{tabular}

VIF = indicator variance inflation factor

\section{Step 2 - Structural Model Evaluation}

Next, the structural model was evaluated using the explained variance $\left(R^{2}\right)$ measure for the endogenous constructs and the path coefficients, to assess the predictive power of the model (Chin, 2010; Hair et al., 2011). The measures for $R^{2}$ of $0.67,0.33$, and 0.19 were considered substantial, moderate, and weak, respectively, and the path coefficients had to be significant (Chin, 2010). Our model of moderator influence accounted for $50 \%$ of the explained variances in the firm's CFP, signifying the moderate relationship that was proposed by Chin (2010). Apart from assessing the $R^{2}$ magnitude, Stone's (1974) and Geisser's (1975) predictive relevance evaluation measure were included as another model fit determinant tool. Chin (2010) postulated that the model exhibits a predictive relevance if the value of the Stone-Geisser $Q^{2}$ (cross-validated redundancy) is greater 
than zero with values of 0.02 to $0.15,0.15$ to 0.35 and above 0.35 were considered weak, moderate and strong predictive power, respectively. The model recorded 0.467 for the average cross-validated redundancy, which was substantially greater than zero, indicating a strong predictive power. The model Sympson's paradox ratio is 0.875 , which fulfil Kock and Gaskins (2016)'s cut-off point. Thus, the model displayed a satisfactory fit and strong predictive relevance. Without the presence of the moderator variable (firm size), the explained variance $\left(R^{2}\right)$ is 0.413 and the Stone-Geisser $Q^{2}$ is 0.414 . Therefore, there is an increase in explained variance $\left(R^{2}\right)$ for CFP by $8.7 \%$ (from 0.413 to 0.500 ) and an increase in the predictive relevance of the model by $5.3 \%$ (from 0.414 to 0.467 ) when firm size was introduced; suggesting the presence of a moderating effect. Next, the path coefficient and hypothesis testing were discussed.

Table 4. Path coefficient and hypothesis testing.

\begin{tabular}{|c|c|c|c|c|c|c|c|}
\hline Hypothesis & Relationship & $\begin{array}{c}\text { Path } \\
\text { Coefficient }\end{array}$ & $\begin{array}{l}\text { Std } \\
\text { error }\end{array}$ & $\begin{array}{c}\text { P- } \\
\text { value }\end{array}$ & $\begin{array}{c}\mathrm{T} \\
\text { ratios }\end{array}$ & $\begin{array}{l}\text { Effect } \\
\text { Size }\end{array}$ & Supported? \\
\hline & Main effect & & & & & & \\
\hline $\mathrm{H} 1$ & $\mathrm{GBP} \rightarrow \mathrm{CFP}$ & 0.086 & 0.068 & 0.102 & 1.272 & 0.044 & No \\
\hline $\mathrm{H} 2$ & GSM $\rightarrow$ CFP & 0.159 & 0.067 & 0.009 & 2.370 & 0.076 & Yes \\
\hline $\mathrm{H} 3$ & GSCM $\rightarrow$ CFP & 0.163 & 0.067 & 0.008 & 2.420 & 0.073 & Yes \\
\hline $\mathrm{H} 4$ & $\begin{array}{l}\text { GPM } \rightarrow \text { CFP } \\
\text { Moderating effect }\end{array}$ & 0.406 & 0.064 & $<0.001$ & 6.348 & 0.238 & Yes \\
\hline $\mathrm{H} 5 \mathrm{a}$ & Size $^{\star}$ GBP $\rightarrow$ CFP & 0.300 & 0.065 & $<0.001$ & 4.602 & 0.051 & Yes \\
\hline $\mathrm{H} 5 \mathrm{~b}$ & 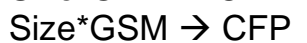 & 0.024 & 0.069 & 0.362 & 0.353 & 0.003 & No \\
\hline $\mathrm{H} 5 \mathrm{c}$ & Size $^{\star}$ GSCM $\rightarrow$ CFP & 0.086 & 0.068 & 0.102 & 1.273 & 0.005 & No \\
\hline $\mathrm{H} 5 \mathrm{~d}$ & Size $^{*}$ GPM $\rightarrow$ CFP & 0.143 & 0.067 & 0.017 & 2.135 & 0.014 & Yes \\
\hline
\end{tabular}

*One tailed test

$\mathrm{GBP}=$ green business practice, $\mathrm{GSM}=$ green supplier management, $\mathrm{GSCM}=$ green subcontractor management, $\mathrm{GPM}=$ green project management

\section{Main effect}

Table 4 presents the results of hypothesis testing. Referring to the main effect, three of the four paths are positive and significant (P-value $<0.05)$; GSM $\rightarrow$ CFP, GSCM $\rightarrow$ CFP, and GPM $\rightarrow$ CFP, supporting $\mathrm{H} 2, \mathrm{H} 3$ and $\mathrm{H} 4$. The strength of the main effect of GPs on 
CFP was examined by the effect size (f2) (Hair et al., 2017), where 0.02 was small, 0.15 was medium, and 0.35 was a large effect (Cohen, 1988). The above results show that green project management has the highest direct effect on CFP $\left(f^{2}=0.238\right)$ with a medium effect, compared to the green supplier management $\left(f^{2}=0.076\right)$ and green subcontractor management $\left(f^{2}=0.073\right)$. However, GBP $\rightarrow$ CFP path was not significant, providing insufficient evidence to support $\mathrm{H} 1$.

In addition, several causality assessments were performed to check the possibility of reverse links between GPs constructs and CFP that may cause bias due to measurement error. As suggested by (Kock, 2017), path-correlation signs, R-squared contributions, path-correlation ratio, nonlinear bivariate causal direction ratios and nonlinear bivariate causal direction differences can be used to identify the presence of reverse link. A negative sign in path-correlation, $\mathrm{R}$-squared contribution $<0.02$, path-correlation ratio $>$ 1.0 , nonlinear causal direction ratio $>1$, absolute nonlinear causal direction differences $>$ 1.3 and $P$ value for absolute nonlinear causal direction difference $\leq 0.05$ are indicators for reverse links in the model. Table 5 presents the results of causality assessments. The results showed that all path-correlations are positive in signs, R-squared contribution are greater than 0.02 , all path-correlation ratios are less than 1.0 , all the nonlinear causal direction ratios are less than 1.0, all absolute nonlinear causal direction differences are less than 1.3 and all $\mathrm{P}$ values for absolute nonlinear causal directions differences are more than 0.05 suggesting that there is no problem of reverse link in the model.

Table 5. Causality assessments 


\begin{tabular}{lcccc}
\hline 1. Path correlation signs & 1 & 1 & 1 & 1 \\
2. R-squared contributions & 0.024 & 0.092 & 0.090 & 0.235 \\
3. Path correlation ratios & 0.093 & 0.395 & 0.440 & 0.681 \\
4. Nonlinear causal direction ratios & 0.993 & 0.969 & 0.896 & 0.984 \\
5. Absolute nonlinear causal direction differences & 0.003 & 0.015 & 0.047 & 0.010 \\
$\begin{array}{l}\text { 6. P value for absolute nonlinear causal direction } \\
\text { differences }\end{array}$ & 0.480 & 0.414 & 0.247 & 0.445
\end{tabular}

\section{Moderating effect}

In terms of the moderating effect, two of the four moderating paths are significant and positive; Size ${ }^{\star}$ GBP $\rightarrow$ CFP and Size*GPM $\rightarrow$ CFP, supporting H5a and H5d. The positive direction indicates that the interaction between GBP $\rightarrow$ CFP and GPM $\rightarrow$ CFP would be greater as the size of firms increases. Referring to Size ${ }^{*}$ GBP $\rightarrow$ CFP, firm size changes the nature of GBP-CFP relationship from the non-significant to the significant relationship and amplifies the effect of green business practice on CFP from $f^{2}$ of 0.044 to 0.051 . In terms of Size ${ }^{*}$ GPM $\rightarrow$ CFP, firm size reduces the effect of green project management on CFP from $f^{2} 0.238$ to 0.014 . These relationships can be better explained via the interaction graphs. Figures 1 and 2 present the relationship between Size*GBP $\rightarrow$ CFP and Size ${ }^{\star}$ GPM $\rightarrow$ CFP, respectively.

Figure 1. Different effects of GBP on CFP across different FSs 
Figure 1 demonstrates that large and smaller firms possess a different moderating effect on the relationship between green business practice and CFP. Large firms with high level of green business practice gained a greater CFP than SMEs. In fact, SMEs experienced a declining CFP when their green business practice increases above the moderate level (mean=3.5); it is shown on a concave down slope. Nonetheless, SMEs with a lower level of green business practice have a better CFP than large firms.

Figure 2 demonstrates that large and smaller firms posed a different impact on the relationship between green project management and CFP. Large firms have an exponential moderating effect on GPM-CFP relationship. Specifically, large firms with a high level of green project management resulted in a higher CFP than SMEs. The high level of GPM implementation still increases the CFP of SMEs, but the effect is lesser than in large firms. On the contrary, SMEs have a higher CFP than large firms with low level of green project management. Large firms perform better financially than SMEs when green project management is implemented meagrely.

Figure 2. Different effects of green project management on CFP across different firm sizes

Likewise, the strength of the moderating effect is not the same. The strength of the moderating effect was examined by the effect size using Kenny's (2016) guidelines; 0.005 was small, 0.01 was medium and 0.025 was large, were followed. The results showed that the highest moderating effect originates from Size ${ }^{\star}$ GBP-CFP relationship $\left(f^{2}=0.051\right)$, 
reflecting a large effect than Size* GPM $\rightarrow$ CFP relationship $\left(f^{2}=0.014\right)$, signalling a medium effect.

\section{DISCUSSION}

The paper analyses the effect of GPs on CFP and investigates whether firm size moderates such effect. Our findings suggest that green supplier management, green subcontractor management and green project management have positive and significant effects on CFP of construction firms. Green project management was found to have the highest effect on CFP. This showed that when the key values of the green concept are deeply ingrained throughout the project cycle from planning, design, construction, and completion, its impact on CFP is the largest as compared to other GP areas. This finding highlights the importance of ensuring that GP is integrated into the design-build or adopting project sustainability management as postulated by Carvalho and Rabechini (2017). In addition, incorporating environmental consideration in the selection criteria for material suppliers, engaging suppliers that adopt environmental management systems and selecting environmental certified or ISO14000 subcontractors increase the firm CFP. The present study found non-significant contributions of green business practice on CFP. One possible reason is that the GP in Malaysia is not very widespread as most effort is focused on public projects (CIDB, 2015). Although GP is adopted as a result of environmental regulations or stakeholders demand, the culture, policy, and operation of construction firms are not well integrated with the environmental agenda. These findings concur with Gotschol et al. (2014) and Miroshnychenko et al. (2017) that the GP-CFP 
relationship of construction firms is varied depending on the areas of GP. Not all GP areas have a positive impact on CFP; therefore, managers of construction firms should focus on green project management, green supplier management and green subcontractor management to gain better CFP.

The present study revealed that firm size and GP degree is of utmost importance for CFP. Our findings showed that large firms enjoy higher CFP only if they adopt high level of green business practice and green project management. Large firms have the capacity for capital, skills and technology slack, provide pool of resources for research and development and linkage with suppliers and secure larger market share. For large firms, high level of green business practice and green project management such as avoiding waste generation or waste to landfil, high level of resource efficiency and recycling of toxic materials or greater investment in environmental management, at enterprise and project levels, gained a higher CFP than SMEs. However, at a lower level of green business practice and green project management, SMEs gained a higher CFP than the large firms. The findings imply that a high level of green business practice and green project management provides a competitive advantage to large firms. In contrast, the low level of green business practice and green project management provides a competitive advantage to SMEs. The findings suggest that, for large firms, the high level of green business practice and green project management are the way forward to compete in the industry. For SMEs, high level of green project management still provides better CFP than low level of green project management, but the SMEs financial performance were lower than the large firms. However, a high level of green business practice is not a viable strategy for SMEs; suggesting that SMEs should not go beyond compliance with 
environmental regulations and SMEs need to balance the degree of pollution control, reduce, reuse and recycle efforts or amount of investment on environment management and financial performance. These findings signal the importance of the appropriate strategies that consider the degree of GP for the construction firms according to firm size to gain a higher CFP.

\section{CONCLUSION}

The paper analyses the effect of GPs on CFP and investigates whether firm size moderates such effect. The findings confirmed that the positive GP-CFP relationships are not the same across various areas of GP and firm size.

\section{Theoretical contributions}

In terms of the theoretical contribution, the present study fills the gaps in the literature in two ways; first, by identifying which GP can increase the CFP of construction firms, the study provides empirical evidence to support the previous postulation of Porter and Van der Linde (1995) on the positive impact of GPs on a firm's CFP; advancing Gotschol et al. (2014) and Miroshnychenko et al. (2017) works by identifying GP areas in the construction industry that had a positive impact on CFP. The present study also confirms the works of Lewandowski (2017) and Song et al. (2017) on the importance of a high level of GP to gain a higher CFP and Simpson (2012), Nguyen et al. (2018), Hou et al. (2016) and Wang et al. (2018) assertions about firm size moderating variance.

\section{Practical contributions}


Practically, the findings pose several implications for businesses in the construction industry to improve their CFP and environment accountability. The significant effect of green project management, green supplier management and green subcontractor management on CFP and the varying influences of firm size on GPs-CFP relationships help practitioners to make strategies by focusing on these three GPs. First, the present study shows that green project management has the highest effect on CFP. Therefore, managers of construction firms should focus on implementing green project management in their projects. Helps from the respective bodies governing the architects and engineers and Construction Industry Development Board in providing training to increase the knowledge, skills and competency on green project management practice among construction practitioners will boost green project management practice and subsequently improve the firms' CFP. Secondly, the government can provide administrative incentive such as fast track project approval and special subsidies to construction firms that implement green project management, green supplier management and green subcontractor management practices to compensate for the additional costs of GP. Thirdly, managers of large construction firms should adopt high level of green business practice and green project management to stay competitive, while SMEs should not go beyond fulfilling environmental regulations or policies. Finally, SMEs should expand their capital, skills and technology if they want to adopt high level green business practice and gain a higher CFP. One option for SMEs is through outsourcing to acquire expert advice on conducting environmental audit and developing effective strategies to implement ISO 14001. Alternatively, the ministry that is responsible for the development of SMEs (e.g Ministry of Entrepreneur Development in the case of Malaysia) 
can implement outreach programs to provide technical assistance for SMEs to implement high level of green business practice such as ISO 14001 and gain higher CFP.

\section{Limitations of the study}

The present study has several limitations. First, the data on GPs and the firms' CFP were collected based on respondent's perception rather than the actual corporate performance data due to the inaccessibility of such data or different forms of actual performance data reported by the firms. If such issues do not arise, future studies could consider the actual corporate performance to investigate the possible differences when using the actual and perceived performance data. Secondly, the present study collected data on GPs and the firms' CFP at one point in time. Several GPs may be short-term, but the effect will only be realised after a longer period (Gotschol et al., 2014; Song et al., 2017). Therefore, a time series research that allows for a longer time period of investigation to track changes in the relationship between variables, will provide valuable results. Finally, our study is restricted to one developing country; Malaysia where the results can be generalised to other upper-middle-income developing economies in Asia, Africa, and South America where GP in the construction industry is limited, despite the countries' development progress (Jiang \& Wong, 2016; Kern et al., 2015; Mastrucci et al.,

2019). However, a global study involving both developed and developing countries is proposed to test and validate the model to provide a holistic understanding of the subject.

\section{References}


Ahmed, W., Ahmed, W., \& Najmi, A. (2018). Developing and analyzing framework for understanding the effects of GSCM on green and economic performance: Perspective of a developing country. Management of Environmental Quality: An International Journal, 29(4), 740-758.

Amran, A., Ooi, S. K., Wong, C. Y., \& Hashim, F. (2016). Business Strategy for Climate Change: An ASEAN Perspective. Corporate Social Responsibility and Environmental Management, 23(4), 213-227. doi:10.1002/csr.1371

Aragón-Correa, J.A.; Sharma, S. A contingent resource-based view of proactive corporate environmental strategy. Acad. Manag. Rev. 2003, 28, 71-88.

Ayuso, S., \& Navarrete-Báez, F. E. (2018). How Does Entrepreneurial and International Orientation Influence SMEs' Commitment to Sustainable Development? Empirical Evidence from Spain and Mexico. Corporate Social Responsibility and Environmental Management, 25(1), 80-94.

Balasubramanian, S., \& Shukla, V. (2017). Green supply chain management: an empirical investigation on the construction sector. Supply Chain Management: An International Journal, 22(1), 58-81. doi:doi:10.1108/SCM-07-2016-0227

Banihashemi, S., Hosseini, M. R., Golizadeh, H., \& Sankaran, S. (2017). Critical success factors (CSFs) for integration of sustainability into construction project management practices in developing countries. International Journal of Project Management, 35(6), 1103-1119.

Carvalho, M. M., \& Rabechini, R. (2017). Can project sustainability management impact project success? An empirical study applying a contingent approach. International Journal of Project Management, 35(6), 1120-1132.

Chang, R.-D., Zuo, J., Zhao, Z.-Y., Soebarto, V., Lu, Y., Zillante, G., \& Gan, X.-L. (2018). Sustainability attitude and performance of construction enterprises: A China study. Journal of Cleaner Production, 172, 1440-1451. doi:https://doi.org/10.1016/j.jclepro.2017.10.277

Chang, C.-H. (2018). How to Enhance Green Service and Green Product Innovation Performance? The Roles of Inward and Outward Capabilities. Corporate Social Responsibility and Environmental Management, 25(4), 411-425. doi:doi:10.1002/csr.1469

Chin, W. W. (2010). How to write up and report PLS analyses. In V. E. Vinzi, W. W. Chin, J. Henseler, \& H. Wang (Eds.), Handbook of partial least squares: Concepts, methods and applications in marketing and related fields (pp. 655690). Berlin: Springer.

Chin, W. W. (2010). How to write up and report PLS analyses. In V. E. Vinzi, W. W. Chin, J. Henseler, \& H. Wang (Eds.), Handbook of partial least squares: Concepts, methods and applications in marketing and related fields (pp. 655690). Berlin: Springer.

Choi, S.-B., Feng, Y., Liu, J., \& Zhu, Q. (2019). Motivating corporate social responsibility practices under customer pressure among small- and medium-sized suppliers in China: The role of dynamic capabilities. Corporate Social Responsibility and Environmental Management, 26(1), 213-226. doi:doi:10.1002/csr.1673

CIDB. (2015). Construction Industry Transformation Programme 2016-2020. Kuala Lumpur: Construction Industry Development Board (CIDB) Malaysia. 
CIDB (2018). Report CITP Q2 2018. Kuala Lumpur: Construction Industry Development Board (CIDB) Malaysia.

Cohen, J. (1988). Statistical power analysis for the behavioral sciences. Hillsdale (NJ): Lawrence Erlbaum.

Craighead, C. W., Ketchen, D. J., Dunn, K. S., \& Hult, G. T. M. (2011). Addressing Common Method Variance: Guidelines for Survey Research on Information Technology, Operations, and Supply Chain Management. IEEE Transactions on Engineering Management, 58(3), 578-588. doi:10.1109/TEM.2011.2136437

Damert, M., \& Baumgartner, R. J. (2018). External Pressures or Internal Governance What Determines the Extent of Corporate Responses to Climate Change? Corporate Social Responsibility and Environmental Management, 25(4), 473488. doi:doi:10.1002/csr.1473

Darnall, N., Henriques, I., \& Sadorsky, P. (2010). Adopting Proactive Environmental Strategy: The Influence of Stakeholders and Firm Size. Journal of Management Studies, 47(6), 1072-1094.

Fornell, C., \& Larcker, D. F. (1981). Evaluating structural equation models with unobservable variables and measurement error. Journal of Marketing Research, 18(1), 39-50.

Franke, George and Marko Sarstedt (2018). Heuristics versus statistics in discriminant validity testing: A comparison of four procedures. Internet Research, forthcoming.

Geisser, S. (1975). The predictive sample reuse method with applications. Journal of the American Statistical Association, 70(350), 320-328.

Georg, F., Jörg, H., \& S., C. P. (2016). Testing moderating effects in PLS path models with composite variables. Industrial Management \& Data Systems, 116(9), 18871900.

Gotschol, A., De Giovanni, P., \& Esposito Vinzi, V. (2014). Is environmental management an economically sustainable business? Journal of Environmental Management, 144, 73-82.

Hair, J. F., Hult, G. T. M., Ringle, C. M., \& Sarstedt, M. (2017). A Primer on Partial Least Squares Structural Equation Modeling (PLS-SEM). Thousand Oaks: Sage.

Hair, J. F., Sarstedt, M., Ringle, C. M., \& Mena, J. A. (2012). An assessment of the use of partial least squares structural equation modeling in marketing research. Journal of the Academy of Marketing Science, 40(3), 414-433.

Hair, J. F., Ringle, C. M., \& Sarstedt, M. (2011). PLS-SEM: Indeed a Silver Bullet. Journal of Marketing Theory and Practice, 19(2), 139-152. doi:10.2753/MTP1069-6679190202

Harmon, J., Fairfield, K. D., \& Behson, S. (2009). A Comparative Analysis of Organizational Sustainability Strategy: Antecedents and Performance Outcomes Perceived by US and Non-US-Based Managers. Paper presented at the The International Eastern Academy of Management Conference Rio de Janiero, Brazil.

Hou, M., Liu, H., Fan, P., \& Wei, Z. (2016). Does CSR practice pay off in East Asian firms? A meta-analytic investigation. Asia Pacific Journal of Management, 33(1), 195-228. 
Jiang, W., \& Wong, J. K. W. (2016). Key activity areas of corporate social responsibility (CSR) in the construction industry: a study of China. Journal of Cleaner Production, 113, 850-860.

Kern, A. P., Dias, M. F., Kulakowski, M. P., \& Gomes, L. P. (2015). Waste generated in high-rise buildings construction: A quantification model based on statistical multiple regression. Waste Management, 39, 35-44. doi:http://dx.doi.org/10.1016/j.wasman.2015.01.043

Ko, W. W., \& Liu, G. (2017). Environmental Strategy and Competitive Advantage: The Role of Small- and Medium-Sized enterprises' Dynamic Capabilities. Business Strategy and the Environment, 26(5), 584-596.

Kock, N. (2014). Advanced mediating effects tests, multi-group analyses, and measurement model assessments in PLS-based SEM. International Journal of eCollaboration (IJeC), 10(1), 1-13.

Kock, N. (2015). Common method bias in PLS-SEM: A full collinearity assessment approach. International Journal of e-Collaboration, 11(4), 1-10.

Kock, N. (2016). Non-normality propagation among latent variables and indicators in PLS-SEM simulations. Journal of Modern Applied Statistical Methods, 15(1), 16.

Kock, N. (2017). Common Method Bias: A Full Collinearity Assessment Method for PLS-SEM. In Partial Least Squares Path Modeling (pp. 245-257): Springer.

Kock, N., \& Gaskins, L. (2016). Simpson's paradox, moderation and the emergence of quadratic relationships in path models: an information systems illustration. International Journal of Applied Nonlinear Science, 2(3), 200-234.

Kock, N., \& Hadaya, P. (2016). Minimum sample size estimation in PLS-SEM: The inverse square root and gamma-exponential methods. Information Systems Journal, n/a-n/a.

Kock, N. (2017). WarpPLS User Manual: Version 6.0. Laredo, TX: Script Warp Systems.

Lam, P. T. I., Chan, E. H. W., Chau, C. K., Poon, C. S., \& Chun, K. P. (2011). Environmental management system vs green specifications: How do they complement each other in the construction industry? Journal of Environmental Management, 92(3), 788-795.

Lewandowski, S. (2017). Corporate Carbon and Financial Performance: The Role of Emission Reductions. Business Strategy and the Environment, 26(8), 1196-1211.

Leonidou, L.C.; Christodoulides, P.; Thwaites, D. External Determinants and Financial Outcomes of an Eco-friendly Orientation in Smaller Manufacturing Firms. J. Small Bus. Manag. 2016, 54, 5-25.

Li, S., Ngniatedema, T., \& Chen, F. (2017). Understanding the Impact of Green Initiatives and Green Performance on Financial Performance in the US. Business Strategy and the Environment, 26(6), 776-790.

Liang, D. P., \& Liu, T. S. (2017). Does environmental management capability of Chinese industrial firms improve the contribution of corporate environmental performance to economic performance? Evidence from 2010 to 2015. Journal of Cleaner Production, 142, 2985-2998. Liu, H., \& Lin, B. (2016). Ecological indicators for green building construction. Ecological Indicators, 67, 68-77.

Lintukangas, K., Hallikas, J., \& Kähkönen, A.-K. (2015). The Role of Green Supply Management in the Development of Sustainable Supply Chain. Corporate Social 
Responsibility and Environmental Management, 22(6), 321-333. doi:doi:10.1002/csr.1348.

Martens, M. L., \& Carvalho, M. M. (2017). Key factors of sustainability in project management context: A survey exploring the project managers' perspective. International Journal of Project Management, 35(6), 1084-1102. doi:https://doi.org/10.1016/j.ijproman.2016.04.004

Mastrucci, A., Byers, E., Pachauri, S., \& Rao, N. D. (2019). Improving the SDG energy poverty targets: residential cooling needs in the Global South. Energy and Buildings.

McPeak, C., \& Tooley, N. (2008). Do Corporate Social Responsibility Leaders Perform Better Financially? Journal of Global Business Issues, 2(2), 1-6.

Miroshnychenko, I., Barontini, R., \& Testa, F. (2017). Green practices and financial performance: A global outlook. Journal of Cleaner Production, 147, 340-351.

Mondéjar-Jiménez, J., Vargas-Vargas, M., Segarra-Oña, M., \& Peiró-Signes, A. (2013). Categorizing Variables Affecting the Proactive Environmental Orientation of Firms. International Journal of Environmental Research, 7(2), 495-500. doi:10.22059/ijer.2013.629

Nguyen, M. H., Phan, A. C., \& Matsui, Y. (2018). Contribution of quality management practices to sustainability performance of Vietnamese firms. Sustainability (Switzerland), 10(2).

O'Connor, J. T., Torres, N., \& Woo, J. (2016). Sustainability actions during the construction phase. Journal of Construction Engineering and Management, 142(7), 04016016.

Oshodi, O., \& Aigbavboa, C. (2017). Theoretical Analysis of the Metrics for Measuring the Sustainability of Infrastructure Projects. In Carbon Footprint and the Industrial Life Cycle (pp. 325-337): Springer.

Porter, M. E., \& Van der Linde, C. (1995). Green and competitive: ending the stalemate. Harvard business review, 73(5), 120-134.

Rao, P., \& Holt, D. (2005). Do green supply chains lead to competitiveness and economic performance? International Journal of Operations \& Production Management, 25(9), 898-916.

Razali, N. M., \& Wah, Y. B. (2011). Power comparisons of shapiro-wilk, kolmogorovsmirnov, lilliefors and anderson-darling tests. Journal of statistical modeling and analytics, 2(1), 21-33.

Rigdon, E. E. (2016). Choosing PLS path modeling as analytical method in European management research: A realist perspective. European Management Journal, 34(6), 598-605. doi: https://doi.org/10.1016/j.emj.2016.05.006

Robinson, M. A. (2018). Using multi-item psychometric scales for research and practice in human resource management. Human Resource Management, 57(3), 739750. doi:doi:10.1002/hrm.21852

Sáez-Martínez, F. J., Díaz-García, C., \& González-Moreno, Á. (2016). Factors promoting environmental responsibility in European SMEs: The effect on performance. Sustainability, 8(9), 898.

Segarra Oña, M. P. S., A.; Ceballos Santamaría, G.; Vargas Vargas, M. . (2013). Unravelling the Relation between the Environmental Proactive Orientation of 
Firms and their Economic Performance. Environmental Engineering and Management Journal, 12(10), 1989-1994.

Shi, Q., Yan, Y., Zuo, J., \& Yu, T. (2016). Objective conflicts in green buildings projects: A critical analysis. Building and Environment, 96, 107-117.

Siew, R. Y. J., Balatbat, M. C. A., \& Carmichael, D. G. (2013). The relationship between sustainability practices and financial performance of construction companies. Smart and Sustainable Built Environment, 2(1), 6-27.

Simpson, D. (2012). Knowledge resources as a mediator of the relationship between recycling pressures and environmental performance. Journal of Cleaner Production, 22(1), 32-41.

Song, H., Zhao, C., \& Zeng, J. (2017). Can environmental management improve financial performance: An empirical study of A-shares listed companies in China. Journal of Cleaner Production, 141(Supplement C), 1051-1056.

Stone, M. (1974). Cross-validatory choice and assessment of statistical predictions. Journal of the Royal Statistical Society, 36(2), 111-133.

Tabassi, A. A., Roufechaei, K. M., Ramli, M., Bakar, A. H. A., Ismail, R., \& Pakir, A. H. K. (2016). Leadership competences of sustainable construction project managers. Journal of Cleaner Production, 124, 339-349.

Torugsa, N.A.; O'Donohue,W.; Hecker, R. Capabilities, proactive CSR and financial performance in SMEs: Empirical evidence from an Australian manufacturing industry sector. J. Bus. Ethics 2012, 115, 483-502.

Trumpp, C., \& Guenther, T. (2017). Too Little or too much? Exploring U-shaped Relationships between Corporate Environmental Performance and Corporate Financial Performance. Business Strategy and the Environment, 26(1), 49-68. doi:10.1002/bse.1900

Wang, J., Zhang, Y., \& Goh, M. (2018). Moderating the role of firm size in sustainable performance improvement through sustainable supply chain management. Sustainability (Switzerland), 10(5).

Wu, G.-C. (2017). Effects of Socially Responsible Supplier Development and Sustainability-Oriented Innovation on Sustainable Development: Empirical Evidence from SMEs. Corporate Social Responsibility and Environmental Management, 24(6), 661-675. doi:doi:10.1002/csr.1435

Yin, S. Y. L., Tserng, H. P., Toong, S. N., \& Ngo, T. L. (2014). An improved approach to the subcontracting procurement process in a lean construction setting. Journal of Civil Engineering and Management, 20(3), 389-403.

Yusof, N. A., Awang, H., \& Iranmanesh, M. (2017). Determinants and outcomes of environmental practices in Malaysian construction projects. Journal of Cleaner Production, 156, 345-354.

Yusof, N. A., Zainul Abidin, N., Zailani, S. H. M., Govindan, K., \& Iranmanesh, M. (2016). Linking the environmental practice of construction firms and the environmental behaviour of practitioners in construction projects. Journal of Cleaner Production, 121, 64-71.

Zhu, Q., Sarkis, J., Lai, K.-h., \& Geng, Y. (2008). The role of organizational size in the adoption of green supply chain management practices in China. Corporate Social Responsibility and Environmental Management, 15(6), 322-337.

doi:doi:10.1002/csr.173 
